\title{
The state of the art in the analysis of two-dimensional gel electrophoresis images
}

\author{
Matthias Berth • Frank Michael Moser • \\ Markus Kolbe $\cdot$ Jörg Bernhardt
}

Published online: 3 April 2008

(C) Springer-Verlag 2008

\section{Erratum to: Appl Microbiol Biotechnol}

DOI 10.1007/s10253-007-1128-0

Due to a technical error, the article "The state of the art in the analysis of two-dimensional gel electrophoresis images" carries an incorrect copyright line. The copyright of the article is with DECODON GmbH, not with Springer-Verlag."

The online version of the original article can be found at http://dx.doi. org/10.1007/s00253-007-1128-0.

M. Berth · F. M. Moser $\cdot$ M. Kolbe $\cdot$ J. Bernhardt

DECODON GmbH,

Rathenau-Strasse 49a,

17489 Greifswald, Germany

J. Bernhardt $(\bowtie)$

Institute of Microbiology, Greifswald University,

Jahnstrasse 15,

17487 Greifswald, Germany

e-mail: Joerg.Bernhardt@uni-greifswald.de 